\title{
Ceratoplastia lamelar profunda com viscodissecção da membrana de Descemet
}

Deep lamellar Keratoplasty with viscodissection of Descemet's membrane

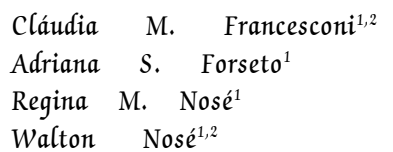

${ }^{1}$ Eye Clinic Day Hospital.

${ }^{2}$ Universidade Federal de São Paulo - Escola Paulista de Medicina (UNIFESP-EPM).

Endereço para correspondência: Al. Franca, 63 - apto. 12 - São Paulo (SP) CEP 01422-000. E-mail: cmfrancesconi @uol.com.br

\section{INTRODUÇÃO}

Nas últimas décadas, com a disponibilidade de material doador bom, novos instrumentais cirúrgicos e um melhor entendimento da fisiopatologia das doenças corneanas que necessitam de transplante, o número de ceratoplastia lamelar realizada diminui drasticamente.

Atualmente, a ceratoplastia lamelar é utilizada principalmente como uma técnica de ceratoplastia terapêutica, na qual a restauração da acuidade visual pós-operatória é freqüentemente pobre ${ }^{(1)}$. Entretanto, a ceratoplastia lamelar profunda, onde o estroma corneano patológico é excisionado até a membrana de Descemet, leva a uma extrema melhora da acuidade visual pósoperatória, sendo favoravelmente comparada a ceratoplastia penetrante ${ }^{(2-4)}$. 
Acredita-se que a ceratoplastia lamelar profunda seja um tratamento efetivo para olhos cuja função endotelial celular esteja preservada $^{(1)}$.

Como vantagem teórica, a ceratoplastia lamelar diminui o risco de falência do transplante devido à rejeição endotelial, pois o endotélio transplantado é o maior alvo de reação imunológica ${ }^{(1)}$. O epitélio transplantado é substituído por células do receptor, pois as células epiteliais do centro corneano são células amplificadoras transientes e não células germinativas $^{(5)}$. As células epiteliais, provenientes das células germinativas do receptor, cobrirão a córnea central dentro de vários meses. Com isso, a ceratoplastia lamelar é um transplante de substrato corneano (fibras colágenas) e de células estromais.

Entretanto, o transplante lamelar tem como desvantagens as dificuldades técnicas e o longo ato cirúrgico, sendo em algumas situações necessárias a utilização de máquinas de criolato $^{(2)}$, e globo ocular inteiro para preparação do botão corneano.

Baseado nestes fatos está analisando a eficácia da técnica de ceratoplastia lamelar profunda com viscodissecção da membrana de Descemet ${ }^{(6)}$ e utilização de botão esclero-corneano preservado.

\section{MÉTODOS}

Foram realizadas 14 ceratoplastias lamelares profundas (14 pacientes) entre o período de fevereiro de 1995 a junho de 1997. Todos os pacientes foram operados pelo mesmo cirurgião. Os diagnósticos pré-operatórios foram: leucoma por herpes simples em 03 olhos $(21,4 \%)$, ceratocone avançado em 10 olhos $(71,4 \%)$ e irregularidade corneana pós-cirurgia de ceratotomia radial em um caso $(7,1 \%)$.

A idade dos pacientes variou de 14 a 46 anos (média de $28,85 \pm 9,78$ anos), destes $08(57,1 \%)$ eram mulheres e 06 $(42,8 \%)$ eram homens.

A anestesia foi realizada com bloqueio peribulbar em todos os casos. A técnica cirúrgica para a retirada da córnea receptora iniciou-se com a trepanação corneana (lâmina descartável, sem guia com $8,0 \mathrm{~mm}$ de diâmetro) superficial (em torno de $2 / 3$ da espessura) para a remoção do estroma anterior. Cuidadosamente, a dissecção foi aprofundada com lâmina de bisturi $\left(n^{\circ} 11\right)$ até chegar ao estroma profundo, podendo-se observar o "brilho" da Descemet. Neste momento, substância viscoelástica - sulfato de condroitina $4 \%$ e hialuronato de sódio 3\% (Viscoat $\left.{ }^{\circledR}\right)$ foi injetada para a separação da Descemet e excisão do estroma remanescente com a tesoura de Vannas. (Figura 1) Para a trepanação da córnea doadora, usamos botão esclero-corneano preservado em Optisol-GS (Chiron, Irvine, Califórnia, EUA). A córnea foi trepanada do lado endotelial para o epitelial com trépano descartável e sem guia de $8,25 \mathrm{~mm}$ de diâmetro, sendo esta utilizada em sua espessura total, com a exclusão apenas do endotélio (raspado com cotonete), e membrana de Descemet (retirada com pinça). A córnea doadora foi posicionada sobre a Descemet do receptor, após

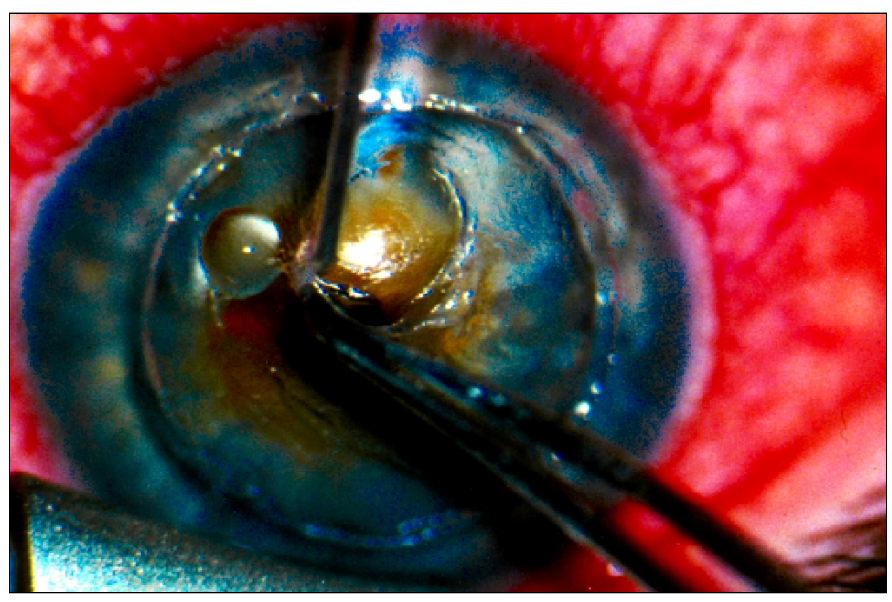

Figura 1 - Viscoelástico sendo injetado para separação da Descemet e excisão do estroma corneano, durante ceratoplastia lamelar profunda. Pode-se observar o "brilho" da membrana Descemet.

copiosa lavagem da córnea receptora com solução salina para evitar aprisionamento de solução viscoelástica na interface. As córneas doadora e receptora foram suturadas com 16 pontos separados de mononylon 10,0 (Figura 2). Ceratoscopia trans-operatória não foi realizada.

RESULTADOS

Os 14 olhos estudados apresentaram acompanhamento pós-operatório médio de 24 meses $\pm 10,58$ ( 12 a 48 meses).

A acuidade visual sem correção pré-operatória era $\leq 20 / 400$ em $71,4 \%$ dos casos ( $\mathrm{n}=10), 20 / 200$ em $21,4 \%$ dos casos $(\mathrm{n}=3)$ e de 20/100 em um caso (7,1\%), evoluindo para uma média de $20 / 125$ na última visita pós-operatória (variando entre 20/30 e 20/400). Destes 10 (71,4\%) apresentaram acuidade visual sem correção no pós-operatório de 20/100 ou melhor.

Depois de retirada de todos os pontos $(12,43$ meses $\pm 1,98)$,

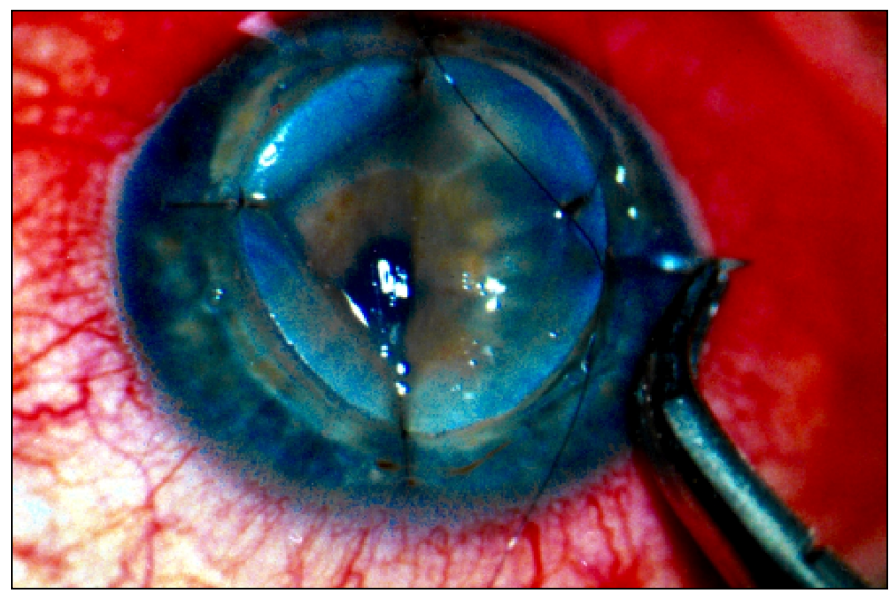

Figura 2 - Sutura do botão doador sobre membrana de Descemet do receptor. Córnea doadora edemaciada, sem endotélio e membrana de Descemet. Sutura com pontos separados de mononylon 10-0. 
o equivalente esférico pós-operatório da última consulta apresentou média de $-2,0 \pm 3,6$ dioptrias (D) $(-10,37 \mathrm{D}$ a $+4,75 \mathrm{D})$. Nesta ocasião, o astigmatismo foi de $-3,3 \pm 1,9 \mathrm{DC}(-6,0 \mathrm{DC}$ a $-0,75 \mathrm{DC})$ e o componente esférico de $-0,4 \pm 3,5 \mathrm{DE}(-9,0 \mathrm{DE}$ a $+6,7 \mathrm{DE})$. Dos 14 pacientes, $03(21,4 \%)$ foram submetidos a Laser in situ Keratomileusis no pós-operatório (15-36 meses), para correção de suas ametropias, sendo nesta época excluídos do presente trabalho.

A acuidade visual pré-operatória com correção $(\mathrm{AVc} / \mathrm{c})$ apresentou-se em 13 casos $(92,8 \%) \leq 20 / 100$ e em um caso (7,1\%) 20/80. Já na última visita pós-operatória a média da $\mathrm{AVc} / \mathrm{c}$ foi de 20/35, variando de 20/20 a 20/80 (Gráfico 1). Dos 14 pacientes, $12(85,7 \%)$ apresentaram $A V c / c$ de 20/40 ou melhor. Um paciente $(7,1 \%)$ apresentou $\mathrm{AVc} / \mathrm{c}$ de $20 / 80$ no $36^{\circ}$ mês de pós-operatório, devido à presença de dobras na membrana de Descemet e catarata subcapsular posterior. Um caso $(7,1 \%)$ apresentou a melhor acuidade visual corrigida de 20/50, também devido à presença de dobras na membrana de Descemet. Todos os pacientes (100\%) apresentaram ganho de linhas da melhor acuidade visual corrigida em relação à tabela de Snellen, variando de 3 a 10 linhas, com uma média de 5,7 \pm 1,8 linhas.

Em nossa série não houve ruptura da membrana de Descemet durante a cirurgia, nem opacificação da interface entre a córnea doadora e receptora (Figura 3). Não foram encontrados episódios de rejeição epitelial ou endotelial em nenhum dos olhos.

\section{DISCUSSÃO}

As duas maiores indicações para a ceratoplastia lamelar são cicatrizes corneanas superficiais e ceratocone com intolerância à lente de $\operatorname{contato}^{(7)}$. Isto pôde ser constatado em nosso estudo, onde o diagnóstico pré-operatório em 71,4\% dos casos foi ceratocone. Alguns autores consideram a vascularização profunda prévia à cirurgia, comum em pacientes pósherpes simples, como uma contra-indicação para esta cirurgia

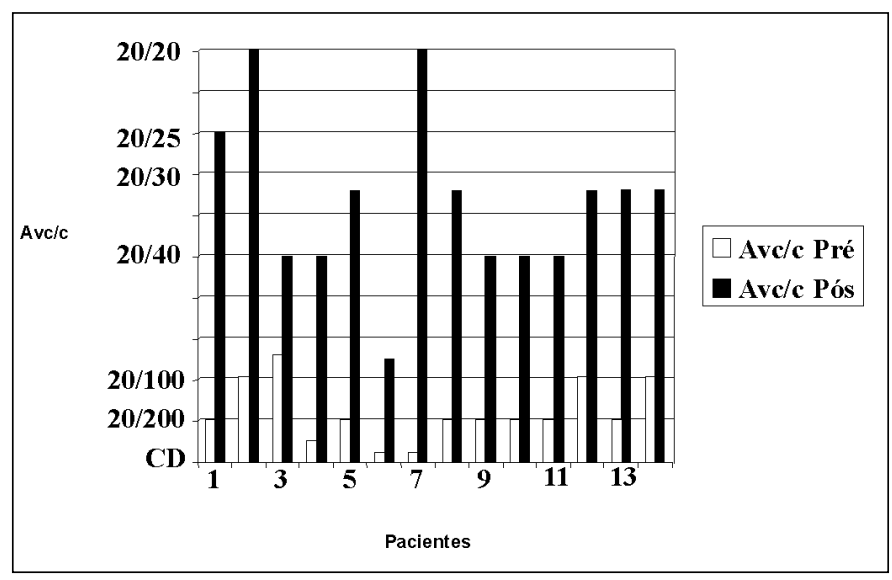

Gráfico 1 - Correlação da acuidade visual pré e pós-operatória na última visita. $(n=14)$ Avc/c = acuidade visual com correção, $C D=$ conta dedos

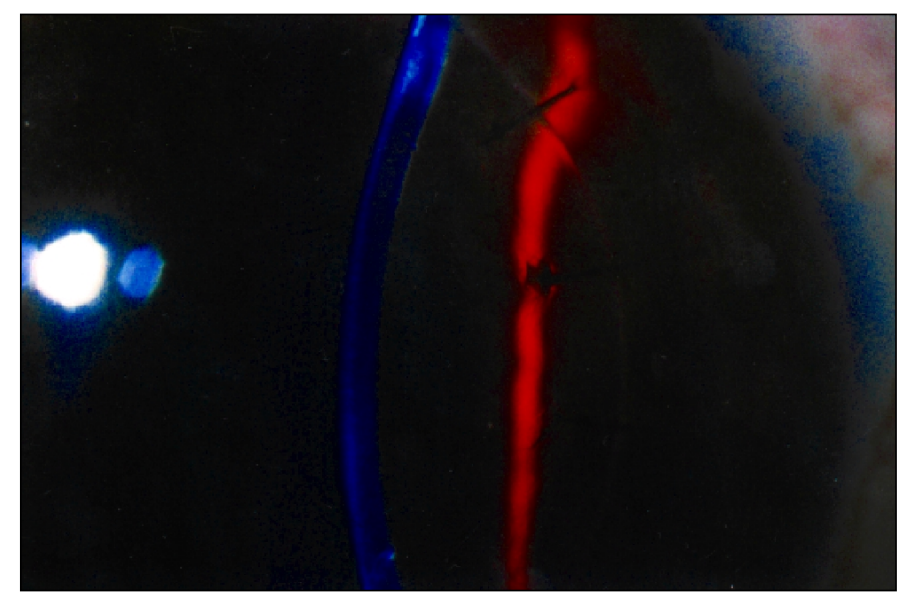

Figura 3 - Ceratoplastia lamelar com interface transparente

pela possibilidade de dar origem a irregularidade da interface e depósitos lipídicos, resultando em baixa acuidade visual ${ }^{(1)}$. Apesar de uma pequena amostragem, dos 3 pacientes com leucoma por herpes simples, um desenvolveu vascularização na interface, periférica e sem prejuízo da acuidade visual. A ceratoplastia lamelar tem inúmeras vantagens sobre a ceratoplastia penetrante: é considerado um procedimento extraocular, tem a necessidade de menor quantia de corticosteróide no pós-operatório, possui ausência de rejeição endotelial, além do endotélio do doador ser irrelevante, com isso, córneas com data de preservação avançada (acima de 14 dias) podem ser utilizadas. Porém tem uma deficiência importante, que é a acuidade visual pobre no pós-operatório ${ }^{(8-9)}$. Por isso que o transplante lamelar tem sido utilizado principalmente para ceratoplastias terapêuticas e não ópticas ${ }^{(1)}$.

É rara a ocorrência de complicação durante a ceratoplastia lamelar, porém a perfuração corneana intra-operatória, com saída de humor aquoso ou câmara anterior rasa, é freqüentemente comum, sendo necessário muitas vezes a mudança da técnica para ceratoplastia penetrante.

Acredita-se que a causa de baixa acuidade visual no pósoperatório seja devido à formação de tecido cicatricial na interface ${ }^{(9)}$, mas isto ainda não foi claramente estabelecido na literatura. Kondo, Sujita ${ }^{(2)}$ sugerem que com a ceratoplastia lamelar profunda seja possível obter melhora da acuidade visual, mantendo as vantagens do transplante lamelar tradicional. Neste estudo, a membrana de Descemet foi exposta somente na área pupilar e a córnea doadora foi preparada em máquina de criolato. Estes autores relatam que não observaram rejeição e que a $\mathrm{AVc} / \mathrm{c}$ após a cirurgia teve uma média de 20/33 após 1 ano de acompanhamento. O astigmatismo pósoperatório foi de $3 \mathrm{D}$, sendo estes resultados comparáveis aos nossos, onde a média da $\mathrm{AV}$ c/c e o astigmatismo pós-operatório foram de 20/35 e 3,3D respectivamente.

Sabe-se que histologicamente a membrana de Descemet é uma membrana basal fina de $10-13 \mu \mathrm{m}$ no adulto $^{(10)}$. Se na córnea doadora o lado endotelial for raspado com um cotonete, a membrana de Descemet pode ser retirada com certa 
facilidade, deixando uma superfície macroscópica completamente regular. Donnelly et al. ${ }^{(11)}$ mostraram que o endotélio pode produzir material antigênico levando a uma resposta inflamatória da córnea e subseqüente dano das células endoteliais remanescentes do receptor, ou cicatrização alterada da interface, resultando em opacificação da mesma.

Se na córnea receptora a membrana de Descemet for exposta, pelo menos de 5 a $7 \mathrm{~mm}$ no eixo pupilar, esta também apresentará uma superfície regular, resultando assim na ausência de tecido cicatricial na interface ${ }^{(12)}$. Esta é provavelmente a razão pela qual ocorre uma melhora significativa da acuidade visual após ceratoplastia lamelar profunda.

Até o presente momento poucas referências foram encontradas na literatura em relação a ceratoplastia lamelar profunda ${ }^{(2,6,8,13-14)}$ principalmente com a excisão total do estroma e exposição da membrana de Descemet, provavelmente pelas dificuldades da técnica.

Foram descritas outras técnicas para ceratoplastia lamelar profunda como a utilização de hidrodelaminação com solução salina para edemaciar o estroma e facilitar sua excisão( ${ }^{(2)}$, e delaminação com ar ${ }^{(8,13)}$ Tsubota et al. ${ }^{(14)}$ descreveram a técnica de "dividir e conquistar" a córnea receptora, que consiste na trepanação e divisão da área trepanada em quatro quadrantes para facilitar a delaminação e excisão do estroma até o aparecimento da membrana de Descemet. A delaminação é realizada utilizando-se ar e água, e o botão esclero-corneano preservado é preparado manualmente. Seus resultados também são comparáveis aos nossos e aos de Kondo e Sugita ${ }^{(2)}$, Tsubota et al. ${ }^{(14)}$ observaram média de $\mathrm{AV}$ c/c de 20/38 e média de astigmatismo ceratométrico de 3,2D no último acompanhamento oftalmológico ( 6 meses).

Com base em nossos dados, concluímos que o uso de ceratoplastia lamelar profunda com viscodissecção e uso de botão esclero-corneano apesar de tecnicamente mais complexa, leva a melhora significativa da acuidade visual e baixo risco de reação imunológica, devendo assim ser mais freqüentemente utilizada.

\section{SUMMAR Y}

Objective: To evaluate the effect of the deep lamellar keratoplasty technique in preserving Descemet's membrane and the patient's endothelial cells, using corneoscleral donor button. Methods: 14 lamellar keratoplasties were performed with viscodissection of the receptor's Descemet's membrane using $4 \%$ chondroitin sulphate and 3\% sodium hyaluronate. Ten (10) patients presented advanced keratoconus, 3 had herpes simplex leucoma and 1 had corneal irregularity due to a previous radial keratotomy. Postoperative follow-up varied from 12 to 48 months (average $24 \pm 10.5$ months). Results: After all sutures had been removed, the spherical equivalent on the last ophthalmic examination was $-2.0 \pm 3.6$ diopters (D) $(-10,3 \mathrm{D}$ to $+4,74 \mathrm{D})$. Final astigmatism varied from $-6,0 \mathrm{CD}$ to $-0,75 \mathrm{CD}$ with an average of $-3,3 \pm 1,9 \mathrm{CD}$. Twelve of 14 patients presented a best spectacle corrected visual acuity of 20/40 or better on the last examination. All patients gained Snellen lines. Postoperatively there was no corneal edema, endothelial decompensation, rejection, interface opacity nor deposits. Two patients developed Descemet's folds accounting for low visual acuity. Conclusion: In spite of technical difficulties related to lamellar keratoplasty and viscodissection of Descemet's membrane, we believe that this is a procedure of choice in patients whose endothelial cells population is preserved. This technique results in better final visual acuity when compared to the traditional lamellar transplant, and less immunologic reaction when compared to penetrating keratoplasty. Because the receptor's endothelium was preserved, surgeries resulted in transparent corneas, regardless of the donor's tissue quality.

Keywords: Corneal transplantation; Descemet's membrane

\section{REFEREN EIAS}

1. Arentsen JJ. Lamellar grafting em: Corneal Surgery - theory, technique and tissue. 2nd ed. Brightbill FS: Mosby-Year Book; 1993. p. 360-7.

2. Kondo J, Sugita J. Deep lamellar keratoplasty with complete removal of pathological stroma for vision improvement. Br J Ophthalmol 1997;81:184-8.

3. Gonçalves EC, Trindade FC. Ceratoplastia penetrante: alterações nas indicações, 1983-1992. Arq Bras Oftalmol 1994;57:274-7.

4. Dantas MCN, Dantas PEC, Holzchuh N, Lui Neto A, Giovedi Filho R, Giovedi M, Almeida GV. Indicações de transplante de córnea. 1991-1995. Arq Bras Oftalmol 1998;61:26-33.

5. Tseng SCG. Concept and application of limbal stem cells. Eye 1989;3:141-57

6. Nosé W, Nosé RAM. Ceratoplastias e ceratectomias. In: Belfort Jr R, KaraJosé N editores. Córnea - clínica e cirúrgica. São Paulo: Roca; 1996.

7. Nosé W, Neves RA, Santos WD, Mendes AG, Nosé RM. Resultados ópticos em ceratoplastia lamelar no ceratocone [resumo]. Arq Bras Oftalmol 1991; 54(4). [Apresentado no 26 ${ }^{\circ}$. Congresso Brasileiro de Oftalmologia; 1991 Set 25-28; Belo Horizonte - MG].

8. Price Jr FW. Air lamellar keratoplasty. Corneal Surg 1989;5:240-3.

9. Richard JM, Paton D, Gasset AR. A comparison of penetrating keratoplasty and lamellar keratoplasty in the surgical management fo keratoconus. Am J Ophthalmol 1978;86:807-1.

10. Hogan MJ, Alvarado JA, Wedell JE. Histology of the human eye. Philadelphia: Saunders; 1971. p. 93-102.

11. Donnelly JJ, Li W, Rochey SH et al. Class II alloantigens induced on corneal endothelium in vivo and in vitro [ARVO abstract]. Invest Ophthalmol Vis Sci 1995;26(suppl):316.

12. Gasset AR. Lamellar keratoplasty in the treatment of keratoconus: conectomy. Ophthalmic Surg 1979;10:26-33.

13. Chau GK, Dilly SA, Sheard CE, Rostron CK. Deep lamellar keratoplasty on air with lyophilised tissue. Br J Ophthalmol 1992;76:646-50.

14. Tsubota K, Kaido M, Monden Y, Satake Y, Bissen-Miyajima H, Shimazaki J. A new surgical technique for deep lamellar keratoplasty with single running suture adjustment. Am J Ophthalmol 1998;126:1-8. 